Cad.Est.Ling., Campinas, (45):79-87, Jul./Dez. 2003

\title{
AFASIA E REFERENCIAÇÃO
}

\author{
MONICA C. GANDOLFO \\ (UNICAMP)
}

\begin{abstract}
This paper describes how a specific subject affected by mild aphasia organizes his turns in general organization as well as in topic organization of conversation. It is analyzed the way reference is established and maintained "on line" and which referential strategies are deployed by the subject.
\end{abstract}

Este trabalho tem como objetivo mostrar a maneira pela qual o sujeito afásico $\mathrm{CI}^{1}$ organiza seus turnos tanto na organização geral da conversação, como, também, na organização tópica da conversação. Isto quer dizer que analisarei de que modo CI passa de um assunto para o outro, ou seja, de que maneira CI introduz as mudanças de tópicos. Se é através do uso de um pronome ou pela repetição ou, ainda, pela introdução de um novo referente.

Segundo Koch (1992), tópico é definido como um segmento de um texto conversacional. Vejamos, então, como a autora trata este assunto: "É verdade que poderíamos dividir (segmentar) um texto conversacional em fragmentos recobertos por um mesmo tópico. Acontece, porém, que cada conjunto desses fragmentos irá constituir uma unidade de nível mais alto; várias dessas unidades, conjuntamente, formarão outra unidade de nível superior e assim por diante. Cada uma dessas unidades, em seu nível próprio, é um tópico. (Ibid:72)

Para poder analisar esta mudança de tópico através do uso referencial, baseio-me na análise distributiva proposta por Marslen-Wilson, Levy and Tyler (1982), em que os autores tentaram construir um modelo cognitivo através desta análise, tendo como base as seguintes formas referenciais: pronome definido, nome, pro-forma, pronome pessoal e anáfora zero. $\mathrm{O}$ trabalho destes autores teve como intenção ver de que maneira a referência é estabelecida e mantida, ou seja, como o ouvinte põe em ação "on line" as estratégias referenciais a partir da informação lexical (co-texto), como, também, pelo contexto discursivo.

Assim, para este trabalho, o que vai interessar é a maneira pela qual CI mantém e introduz um novo referente. Isto é feito por repetições de nomes já dado, por pronomes, por expressões definidas ou elipses? Ou será que os elementos referentes retornam dentro de cada episódio ou remetem a outros?

É importante salientar, em concordância com Koch \& Marcuschi (1998), que o ato de referir não é visto como uma atividade de "etiquetar" o mundo, mas como uma atividade discursiva, de tal modo que os referentes passam a ser "objetos de discurso" e não realidades independentes, que préexistem ao discurso. Segundo Buin (2000; apud Koch 1997:171) "expressões que retomam referentes principais ou temáticos (como protagonista e antagonista, na narrativa, ser que é objeto de uma

${ }^{1}$ CI é portador de uma "afasia leve", termo este que discuto ao longo da tese de doutorado, no sentido de entender sobre o termo "leve" - ("leve" em relação a quê?; é em relação à extensão da lesão? A linguagem com poucos comprometimentos?) - abrindo, assim, a possibilidade de questionar as classificações tradicionais das afasias. 
descrição, tema de uma discussão) percorrem em geral o texto inteiro, formando cadeias mais longas". (Ibid:40).

Dentre as várias expressões coesivas responsáveis pela (re) ativação do referente no texto, tais como: nomes, artigos definidos, pronomes, elipses, sinônimos, hiperônimos, etc., citarei alguns exemplos da fala de CI extraído do corpus obtido nos encontros do grupo de afásicos realizados no $\mathrm{CCA}$, a fim de que se possam avaliar as estratégias referencias utilizadas por este sujeito cérebro lesado.

O início da sessão se dá com a pesquisadora falando sobre a necessidade deles construírem um livro, para que a comunidade, de um modo geral, saiba o que é afasia. Este será o tópico principal desta sessão e, através dele, vários outros sub-tópicos vão sendo introduzidos (ver anexo 1).

O trecho selecionado foi o da sessão de (16/06/1999) que compõe-se de quatro sub-tópicos: "livros técnicos", "informação que deve conter o livro", "depressão" e "aposentadoria". Cada um destes sub-tópicos, por sua vez, se decompõe em segmentos tópicos: o sub-tópico "livros técnicos" é formado pelo segmento tópico "não auxiliam os pacientes, nem os familiares". Já o sub-tópico "informação que deve conter no livro" é formado pelos segmentos tópicos "funcionamento do cérebro" e "sobre as experiências de cada um". O sub-tópico "depressão" subdivide-se em quatro segmentos tópicos: "entrando em contado com a doença", "fuga dos amigos, "perda da ocupação" e isolamento social". Finalmente, o sub-tópico "aposentadoria" gera apenas um segmento de tópico: "afasia não é considerada nas leis trabalhistas. É interessante lembrar que o segmento tópico: "entrando em contato com a doença" gera um outro segmento que diz respeito a "aposentadoria", que será retomada mais adiante (94 e 96) como um outro sub-tópico (ver anexo 1).

A questão, agora, é apontar as marcas formais que possibilitam a CI fazer cada uma destas passagens, ou, muitas vezes, acompanhar as passagens introduzidas pela examinadora. Vejamos como isto se dá ${ }^{2}$ :

(1) Iem: Isso, é !Então nesse livro, por exemplo, tem várias coisas que vão nos interessar, né ? Então a gente vai lá nos capítulos, por exemplo, tem informações de que ordem? não só de ordem , informações importantes, informações, é ... sobre saúde, sobre neurologias, mas, mas fala sobre o quê? Fala sobre a família da pessoa, fala sobre o impacto que a afasia tem na vida de cada um, na vida dos seus familiares, a questão do trabalho, né ? fala sobre ãh ... a inserção social muitas vezes tem que ser retomada quando a pessoa fica afásica, fica longe do trabalho, às vezes fica um poco fora ... e assim vai ! tudo é importante dizê, mas a nossa estratégia, era otra aqui, não era ? era parti, dos depoimentos. Era ... dos depoimentos fazê so ... fazê ... saltá as informações necessárias que ia tê num livro de divulgação. Não só um livro científico, pra isso tem muito livro aí, livro de informação. Mas é um livro que consiga tocá né ? um livro que consiga tê impacto, é ... sobre as pessoas. E o depoimento, muitas vezes, ele é capaz de fazê isso! Não é verdade, quando você lê um livro de autobiografia, depoimento, fala: "olha ! a pessoa viveu aquilo" né? não é que é um cientista falando sobre as conseqüências da afasia, é um livro das pessoas compartilhando , né de problemas práticos, de questões que efetivamente foram vividas, né? foram superadas, enfrentadas. Muitas vezes a gente pode ajudar as outras pessoas só por conta disso. Por conta da compartilha de ... de experiências. Então é isso!

(2) CI: Posso falá ?

(3) Iem: Claro !

(4) CI: Eu-eu-eu-eu-eu depois do derrame, eu procurei livros, né ? lá na biblioteca ... livros é pra ... entendê, o que aconteceu comigo, né ? Não encontrei livros, só livros muito, ca... é ? muito é-

\footnotetext{
${ }^{2}$ Normas de transcrição: Iem e Imc são investigadoras; CI, EF e DI são os sujeitos afásicos que participam da sessão.
} 
é-é voltados pra professores, né ? professores, com palavras difíceis, eu perdi as palavras, né ? lembra, né ? eu perdi as palavras, aí eu achei é-é-é eu achei um-um-uma enciclopédia é-é-é pra ensi ... pra-pro-pra-pra enfermeiro, né ? pra enfermero, é-é-é aí eu achei a parte de afasia, e a parte de derrame cerebral. Boa! Mas pra enfermero!

Neste primeiro exemplo, CI retoma o elemento referente "livro" através do próprio nome "livro", porém ao introduzir um novo referente "uma enciclopédia", o faz através de um artigo indefinido.

É interessante notar, também, que CI remete a outros elementos da situação comunicativa fazendo uso daquilo que Marcuschi (2000) descreve como sendo a anáfora indireta baseada em esquemas cognitivos, fazendo uso de seu conhecimento prévio sobre livros, permanecendo, assim, dentro de um mesmo frame: livros \pm biblioteca \pm professores \pm enciclopédia. Sobre esta questão, a de "ancorar" em elementos discursivos para ativar ou introduzir um referente novo como se fosse dado, remeto-me a Marcuschi (2000) onde me utilizo de suas palavras para melhor explicar esta situação: “As AI (anáforas indiretas) baseadas em esquemas cognitivos e modelos mentais são aquelas ancoradas em representações conceituais ou relações cognitivas encapsuladas em modelos mentais comumente chamados de frames (enquadres), cenários esquemas, scripts, etc. que representam focos implícitos que se acham armazenados em nossa memória de longo prazo como conhecimento de mundo organizados"(Ibid:10). Cada um destes SN (livro - biblioteca - professor - enciclopédia) não parecem reativar um referente prévio, mas sim ancorar no texto precedente.

Apesar de CI fazer pouco uso de elementos referenciais que não seja det.+ nome ou simplesmente nome, faz uso de anáforas indiretas, como no exemplo acima, baseado em modelos mentais.

Neste próximo trecho, veremos que em (15) CI vai generalizando, cada vez mais, os SNs, no sentido de enfatizar ou marcar a falta de conhecimento que ele supõe que exista sobre o cérebro, tanto por parte dos especialistas como "o mundo inteiro". Isto acaba provocando um efeito de sentido de que "ninguém sabe nada sobre o cérebro". Já em (19), CI se utiliza de um tema marcado (perda de neurônio), mas sem a retomada pronominal, isto é, com elípse.

Segundo Koch (1997), a língua possibilita uma variedade de formas de expressão e a construção dos sentidos no texto depende, em grande parte, das escolhas que cada sujeito realiza. A articulação tema-rema constitui uma destas possibilidades, sendo as estratégias de segmentação uma maneira de desvelar um não dito de certa forma presente à elaboração de toda e qualquer produção de linguagem, pois possibilita a distinção do que é posto e o que é pressuposto e estabelecem as próprias condições de existência do discurso. Esta estratégia de construção do texto falado, tematização e rematização, é bastante utilizada por CI, como teremos a oportunidade de ver ao longo desta trabalho.

Em (21), CI usa o pronome demonstrativo "isso" referindo-se a porções do texto antecedentes tais como: "como o cérebro funciona", "de que maneira a lesão cerebral afeta o funcionamento do cérebro", usadas pela investigadora. Já em (22), CI usa o elemento coesivo catafórico no sentido de focalizar um segmento textual. Vejamos:

(5) Iem: O Cícero, você acha então, que livros, sobre afasia, sobre as conseqüências da afasia, como convive com a afasia, seria importante pra pessoa que fica afásico ?pra familiares e amigos? ...

(6) $C I$ : [ é-é-é ...

(7) EF: [ ô, ô !

(8) $C I$ : Não tem livro, é incrível !

(9) Iem: Mas tem que numa linguagem que não, não só científica !

(10) EF: Ah, ah !

(11) Iem: O senhor acha que vai na parte de // ininteligível por sobreposição//... 
(12) EF: [ vai-vai ...

(13) Iem: ... falando sobre o cérebro, como ele funciona,

(14) EF: [ ô, ô, ô....

(15) $C I$ : Nós sabemos que, nós sabemos que perdemos neurônios, ninguém sabe, os médicos não sabem, os cientistas não sabem que neurônios perdemos, ninguém sabe, o mundo intero não sabe ...

(16) $\mathrm{EF}:[/ / \mathrm{ri} / /$

(17) CI: ... descobrindo, né ? tem cientista que tá descobrindo, pra descobrí que neurônios perdemos!

(18) Iem: Mas tem coisa importante que tem que sabê também, sabê por quê? ...

(19) CI: Agora nós que perdemos neurônios, porque nós temos al-al-al-al o braço, a perna mas que ne-ne-ne-ne normal mas que não funciona. Por que não funciona ? Neurônio que , que trocô, neurônio é-é-é que cria! neurônio trocô ! Aí vai muitos anos pra educá de novo ! Educá como ?

(20) Iem: Então uma coisa que é importante sabê, é como o cérebro funciona, de que maneira o, a lesão cerebral afeta o funcionamento do cérebro ...

(21) $C I$ : Isso é-é importante ! no livro ...

(22) Iem: Agora não só que neurônio é perdido, uma informação que também é importante, que eu acho que é menos sabida que essa, que é o seguinte: o cérebro também se regenera ! não é só que o cérebro fica alterado e morto! morreu neurônio! Vejamos:

É apenas em (26) que CI introduz um novo sub-tópico, até então só feito pela investigadora.

(23) Iem: e se a gente fizesse o seguinte : acho, concordo também com o seu Edmundo, que uma parte sobre a ... uma parte sobre o funcionamento do cérebro e como ele é afetado pela lesão cerebral, é importante ter, mas talvez também seja importante ter como ele é plástico, como ele se regenera, como é importante também fazê que ele volte a funcionar etc.

(24) Imc: O que é importante fazê pra que isso ocorra, o é importante ?

(25) Iem: Exato !

(26) CI: agora, cada um , cada um particularmente tem é ... um tem uma experiência própria !

(27) EF: é, ô, ô !...

(28) $C I$ : ... é e otra ... // ininteligível // o livro, é cheio de experiência ...

(29) Iem: ... cheio de estórias ...

(30) CI: Cheio de estórias, parecidas, parecidas, com eu, com ele, parecidas ... mas própria, cada um é própria! por que, essa particularidade ? porque as pessoas são diferentes! são diferentes!

Quando CI utiliza-se desta expressão referencial: "agora, cada um, cada um particularmente tem é...um tem uma experiência própria”, marca uma fronteira de parágrafo, introduzindo, com isto, um novo sub-tópico: "a experiência de cada um”. Já em (30), é possível visualizar sinais que demonstram que CI está passando para um estágio seguinte em sua argumentação por meio de um encapsulamento. Segundo Koch (1999), encapsulamento "trata-se de função própria particularmente das nominalizações, que sumarizam as informações - suporte contidas em segmentos anteriores do texto, encapsulando-as sob a forma de um substantivo-predicativo e transformando em objetos-dediscurso. (Ibid:10).

Já em (32) CI introduz um novo sub-tópico - a depressão - através de um elemento coesivo catafórico, além do que, tematiza ou faz uso de um tema marcado ao dizer "todo mundo". Já o pronome demonstrativo "isso" também ocupa o lugar de tema: Todo mundo \pm (tema marcado) [isso \pm (tema) acontece (com eles) \pm (rema) é-é... depressão]]. Segundo Koch (1997), “os conceitos de tema 
e rema em questão são aqueles postulados pelos autores da Escola Funcionalista de Praga, ou seja: do ponto de vista funcional, cada enunciado divide-se em (pelo menos) duas partes - tema e rema a primeira das quais consiste no segmento sobre a qual recai a predicação trazida pela segunda" (Ibid:72). Vejamos:

(31) Iem: E a reação de cada um de vocês deve tê sido diferente! quando ficô afásico, né? as histórias do livro mostram um poco. Tem gente que recebeu isso de uma manera, de otra manera, a afasia deve tê tido um impacto " $\mathrm{X}$ " ou "Y" ...

(32) CI: É importante, todo mundo isso acontece, é-é ... depressão!

(33) Iem: Depressão?

(34) CI: Cinco mês depois todo mundo tem depressão, porque é-é-é a hora que volta, né?

(35) Iem: A hora que volta ...

(36) $C I$ : A hora que volta pra recuperá, tá tudo muito é-é-é o pé, o braço, tá tudo muito é-é ... tá muito é ... ninguém sabe, né?

(37) Iem: A depressão vem porque cê acha, Cícero?

(38) CI: Hoje é-é-é descobre, né ? é ... a gente. com dois, três mês, é ... comé que chama? é ... meio, meio é ...// ininteligível // descobre que é afasia, depois de três mês ...

(39) Iem: Tá meio impactado, né ? Não soube o que houve ...

(40) CI: Depois de três mês, aí-aí o corpo tá normal, né ? começa a ficá normal, demora pro corpo ficá normal, aí descobre que é hemiplegia, e afasia ... aí-aí-aí perde, começa, começa senti que perdeu muitas coisas por causa da afasia.

(41) Imc: Aí que vem a ...

(42) CI: Estudo, tudo ... aí começa ...

(43) Iem: Cê também sentiu isso, Dinho?

(44) DI: Ôh!

(45) $C I$ : Todo mundo!

(46) Imc: É quando entra em contato?

(47) CI: Não ! Cinco mês depois! seis mês depois!

(48) Imc: Então, quando começa a entrá em contato com o que perdeu, é isso?

(49) Iem: Começa a avaliá o impacto que teve sobre o corpo, sobre a fala ...

(50) CI: // ininteligível // quando eu tive problema de depressão, eu queria morrê, aí Jesus me salvô, graças a Deus! eu superei, né ? essa afasia, essa depressão! Todo mundo passa depressão!

(51) Iem: Você acha?

(52) $C I$ : Claro que ...

(53) EF: [ Nã, nã, não ...

(54) Iem: O senhor confirma isso?

(55) $C I:[$ não era, não era ...

(56) Imc: O senhor não sentiu depressão?

(57) EF: Não ...

(58) Imc: Não?

(59) EF: Não ...

(60) $C I$ : Porque tinha médico na hora, família tudo ... mas a gente sente muita coisa. E a -e a -e a, a-a-a- depressão, é-é-é, a afasia, não é considerada pra aposentadoria, não é ...

(61) Imc: É, isso daí é importante ...

(62) CI: ... então a aposentadoria não é pra-pra depressão, só a hemiplegia, né? não é hemiplegia, é falta e tra ... de continuá a exer a trabalhá, voltá a trabalhá. Aí aposenta, aposenta por invalidez.

(63) Iem: Tá.

(64) $C I$ : Mas a afasia não é aposentadoria ... 
(65) Iem:[ qué dizê: além de toda dificuldade que a pessoa tem, com relação ao corpo, com relação à fala, tem outras, na verdade por conta disso, a falta do trabalho, a ausência de círculo social, qué dizê, isso também é uma coisa que afeta.

(66) CI: Foge, todo mundo foge!

(67) Imc: // ininteligível // perdas, qué dizê ...

(68) CI: Os parente, até os parente foge ...

(69) Iem: É mesmo?

(70) $C I$ : É, até os parente foge. Só pai, mãe irmãos que não!

(71) Imc: Mas talvez fujam porque nao sabem lidá ...

(72) CI: Não sabem lidá quantos, quantos, quantos, quantos afásicos tem no Brasil? tem no Brasil?

(73) Imc: // ininteligível // muitos, muitos ...

Como já foi dito anteriormente, este sub-tópico (depressão) vai gerar quatro segmentos tópicos: "entrando em contato com a doença", "fuga dos amigos", "perda da ocupação" e isolamento social". O primeiro deles é introduzido pela Inv. em (46), porém, quando CI fala sobre o porquê de sua depressão, introduz mais um elemento que é a aposentadoria (60), voltando a se remeter a ela, no final da sessão, quando argumenta que a afasia não é considerada nas leis trabalhistas (94) e (96).

Em (50), podemos ver que CI ao dizer: "essa afasia, essa depressão", remete, através de um pronome demonstrativo, a seqüência expressa ou subentendida no contexto precedente, retomando o elemento tematizado no interior do enunciado: "problema de depressão".

Em (65) quando a investigadora fala sobre a "ausência de círculo social", gera o segmentotópico introduzido por CI "fuga dos amigos", em (66), onde CI recategoriza por meio de uma nova predicação: "Foge, todo mundo foge".

No trecho seguinte, que vai de (74) a (80), CI introduz o tema da "perda da ocupação", através de expressões que designam um domínio de referência (frame), sendo o elemento de retomada um dos elementos deste domínio: trabalhador - trabalho - empresas. Ou seja, o elemento de retomada pode remeter a algum conhecimento pressuposto pelo SN tematizado, no caso, a "ocupação". Isto é o que podemos ver em (87): "quem é trabalhador, aí sente muita falta..." "perde o trabalho; perde o trabalho! Porque as empresas não considera é-é-é... quem gosta de trabalhá!”. Vejamos:

(74) $C I$ : Rico, rico é-é-é ... rico que tem empresa tal, a-a-a-a afasta, fica uns seis mês fora, um ano fora, volta até firmas normal. Quem é trabalha ...

(75) Iem: Trabalhador ...

(76) CI: Quem é trabalhador, aí sente muita falta ...

(77) Iem: Por que ?

(78) CI: Perde o trabalho; perde o trabalho !Porque as empresas não considera é-é-é ... quem gosta de trabalhá!

(79) Imc: [ Hum, hum ... qué dizê: uma vez que você não consegue falá direito, já era!

(80) $C I: / /$ ininteligível // aí fica muito, muito deprimido, né? muita gente morre, já descobriu que pessoas se matam, porque, e ... ninguém sabe, sai no jornal, mas ninguém sabe. Por que?

Quanto à função de tematizar, remeto-me a Koch (1997):

"Pode-se dizer que, de modo geral, ao recorrer às construções com tema marcado, o falante seleciona um elemento (estado das coisas, propriedades, relação, coordenada espacial ou temporal, indivíduo ou grupo de indivíduo, etc.) que deseja ativar ou reativar na memória do interlocutor e sobre a qual seu enunciado deve lançar nova luz, para apresentar a seguir algo que considera desconhecido por este, que deseja enfatizar ou com o qual pretende estabelecer algum tipo de contraste" (Ibid:84). 
No trecho a seguir, CI continua a falar sobre a depressão, mas, agora, devido ao isolamento social, tópico este introduzido pela INV.:

(81) CI: [ Otra: as famílias, as famílias ... eu consigui saí, graças a Deus eu consegui saí! porque eu tava muito deprimido, né? aí minha esposa // ininteligível // ...

(82) Imc: Claro ...

(83) $C I$ :... e eu recuperei. A família protege muito e tem muitos afásico, muitos hemiplégico que, que tá em casa! que não sai de casa!

(84) Iem: Qué dizê: não só não tem tratamento, como tá apartado da vida ...

(85) $C I$ : Um rapaz que mora pertinho de casa, pertinho é-é-é ... hemiplégico e afásico! // ininteligível // A família protege e não sai de casa!

(86) Imc: É, esconde ...

(87) Iem: Isso revela um ...

(88) Imc: preconceito ...

(89) $C I$ : Os irmão sai, as irmã sai, ele não sai de casa!

É em (83) e (85) que CI utiliza-se de um elemento referencial através de uma recategorização dada por uma nova predicação: "não sai de casa". Já em (89) antepõe o rema, criando, assim, um efeito de sentido em que a única pessoa que não sai de casa é o sujeito afásico: [Os irmão sai, as irmã

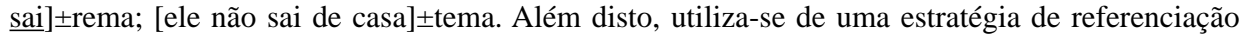
anafórica que permite ao interlocutor recuperar através do pronome pessoal (ele) o sujeito afásico.

Deste trecho em diante, CI retorna ao segmento tópico, aposentadoria, já mencionado anteriormente, gerando um outro segmento-tópico: "afasia não é considerada nas leis trabalhistas", introduzido pelo próprio CI (96). Vejamos:

(90) CI: Olha ! eu // ininteligível // afásico ; eu paguei 20 anos de seguro, né ? eu paguei seguro pra aposentadoria, vinte, vinte anos eu paguei seguro pra aposentadoria, perdi!

(91) Imc: Que qué dizê: descartô afásico ? qué dizê, não considera que ...

(92) CI:// ininteligível // afásico, não considerô nada, só ele considerô uma questão: que a firma de ... é ... São Paulo, Campinas, Paraná, Porto-Alegre, é-é ... uns dois, uns dois anos, considerô somente que era direito pagá o valor // cf fita // então eu ganhei vinte e cinco por cento ...

(93) Imc: Deixa só eu fazê uma pergunta, Cícero: se ele não considerasse a afasia, e // ininteligível // quer dizê o quê ? que se considerasse podia tê otra perspectiva de emprego, uma otra realidade, é isso?

(94) $C I$ : Eu poderia sê aposentado por .... é isso! é isso ! não é, não é ...

(95) Imc: Não precisaria sê aposentado compulsoriamente ...

(96) $C I$ : Não, a lei-a lei- as leis trabalhista diz que a afasia não é problema de aposentadoria!

Em (92), podemos ver que CI faz uso, novamente, da estratégia de rematização, como já foi visto em (89), ou seja, ele antepõe o rema - [afásico] - ao tema [não considerô nada]. Segundo Koch (1997) a estratégia de rematização está diretamente ligada à expressividade e ao envolvimento do falante com o assunto e com o interlocutor. É interessante perceber, também, que ao dizer: "afásico não considerô nada, só ele considerô uma questão", faz uso da estratégia de referenciação anafórica remetendo o interlocutor, por um processo de inferenciação, ao que já havia sido dito antes, no caso, o seguro. 


\title{
CONCLUSÃO
}

Tendo em vista a organização geral da conversação do sujeito cérebro lesado CI, parece-me possível concluir que ele se utiliza dos seguintes itens de referenciação:

- Anáforas Indiretas baseadas em esquemas cognitivos

- Determinantes + nomes

- Estratégias de construção através da articulação tema-rema

- Encapsulamento

- Estratégias referenciais anafórico e catafórico

- Recategoriza por meio de nova predicação

Outros usos referenciais, tais como aqueles proposto por Marslen-Wilson, Levy \& Tyler: próforma, anáfora zero, não foram encontrados na fala de CI, demonstrando, assim, que permanece com sua prática discursiva.

A titulo de conclusão, transcrevo aqui parte das reflexões de Morato (2001) sobre a referenciação como prática discursiva, para melhor ilustrar como o sujeito afásico ao perder a linguagem permanece com esta capacidade, vejamos:

\begin{abstract}
"Com relação ao que ocorre com a linguagem de afásicos ou de sujeitos cuja linguagem tenha sido afetada por algum dano córtico-cognitivo, as discussões em torno do pathos da linguagem estão sempre marcadas - ao longo de nossa trajetória científico-filosófica - por um discurso logocêntrico, cujo compromisso com a questão da referência tem sido reduzida ao referencialismo, ao conhecimento metalingüístico do mundo, à busca da presença da lógica na linguagem (em detrimento de uma lógica $d a$ linguagem). Para muitos esta seria a grande perda sofrida pelo sujeito afásico: a capacidade de, através da linguagem, localizar (e localizar adequadamente!) os objetos do mundo, ou os "objetos do discurso" (Cf. Mondada \& Dubois, 1995) - se quisermos fugir às clássica dicotomias, como língua/exterioridade ou linguagem e mundo. Como ponderei no artigo anterior (2000), a linguagem cuja perda é lastimada é, na verdade, uma fantasmagoria, fruto de uma percepção idealizada que os homens têm feito de si mesmo, de seus cérebro e de seus comportamentos". (Ibid, 2001:5).
\end{abstract}

\section{REFERÊNCIAS BIBLIOGRÁFICAS}

GRICE, H.P. (1986) "Lógica e conversação", in. Pragmática vol.IV - Problemas, críticas, perspectivas da lingüística-bibliográfica.Marcelo Dascal (org.). Campinas. Unicamp.

BUIN, E. (2000) “A referenciação no processo de aquisição da escrita.” Dissertação de Mestrado. Unicamp.

KOCH, I.G.V. (1992) A inter-ação pela linguagem. São Paulo. Contexto. (1997) O texto e a construção dos sentidos. São Paulo. Contexto.

(1999) A construção discursiva da referência. mimeo.

MORATO, E.M. (2000) “As afasias entre o normal e o patológico" in Direito à Fala - a questão do preconceito lingüístico (orgs. Fábio Lopes \& Heronides Moura). Florianópolis. Insular.

(2001) (In)Determinação e Subjetividade na Linguagem de Afásicos: a inclinação anti-referencialista dos processos enunciativos (no prelo).

MARCHUSCHI, L.A. (2000) “Anáfora Indireta: o barco textual e suas âncoras”, in VII Jornada Celsul. Mimeo.

MARSLEN-WILSON, W.\& LEVY, H. \& Tyler, L.K. (1982) Producing interpretable discourse: the establisment and maintenance of reference. Em Jarvella, R.J. e W.klein.1982. Speech,place and action. J. Wiley. pp.339-378. 


\section{ANEXO}

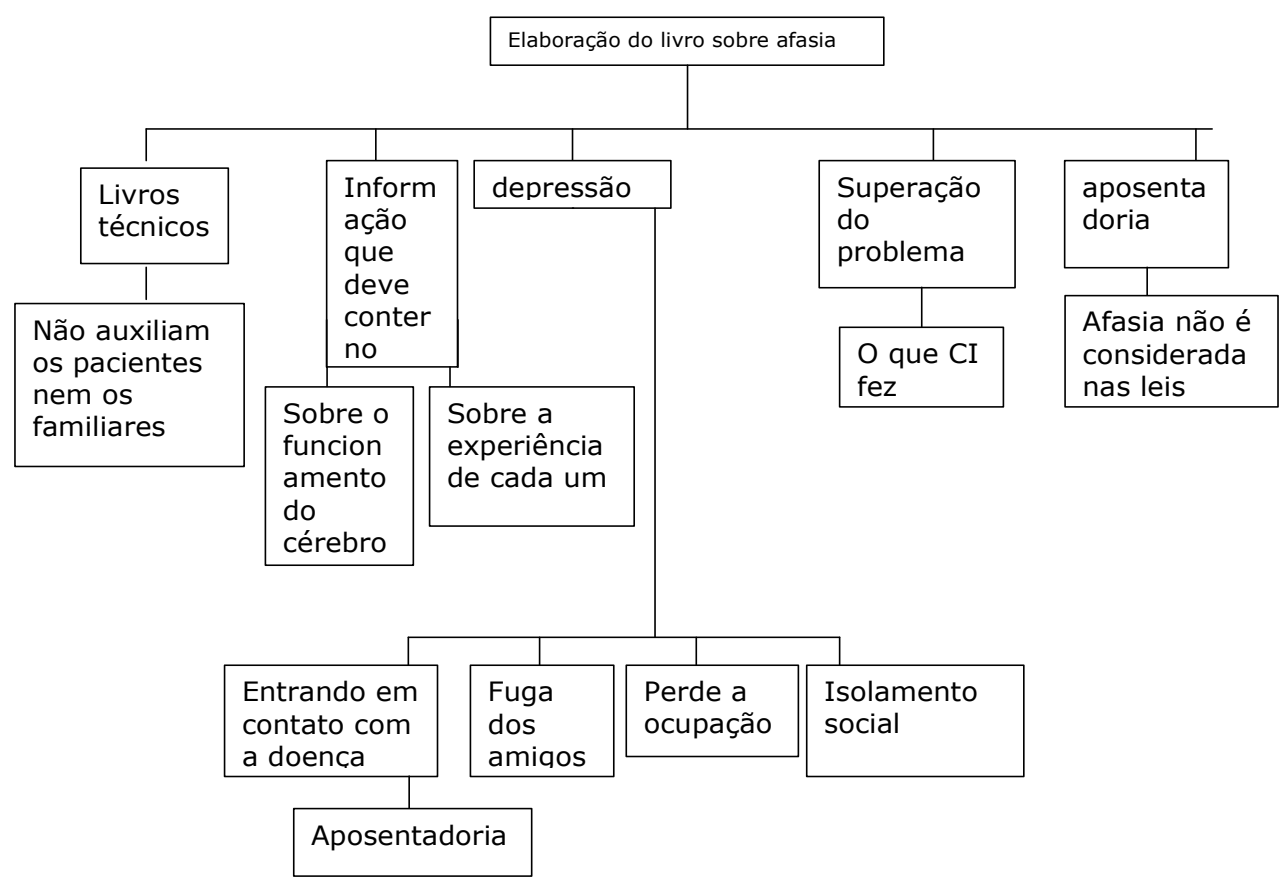

